\title{
The Effect of Physical Activity Program of Elderly in Rural Areas on Life Satisfaction
}

\author{
IJCRR \\ Section: Healthcare \\ Sci. Journal Impact \\ Factor: 6.1 (2018) \\ ICV: 90.90 (2018)

Young Hee Nam

Department of Health administration NamseoulUniversity, Chungnam, Korea.

\section{ABSTRACT}

Introduction: The age standard for the elderly varies slightly depending on the statute or the viewpoint, but the Elderly Act and the WHO define an elderly person as someone aged 65 years and older.

Aim and Objective: This study was to influence of perceived health status and falling efficacy on life satisfaction in elderly performing physical activity program.

Method: The 12-week physical activity program was applied to the public health clinic in $\mathrm{H}$ City of Korea from January to March 2019 , and the evaluation was conducted before and after the program was applied. The data collected from 34 subjects were analyzed by SPSS 23.0.

Result: The ratio of women was $94.1 \%$, and the average age was $76.09( \pm 7.37)$. The number of chronic diseases was the highest with $2(41.2 \%)$ and the average was $2.29( \pm 1.24)$. Life satisfaction perceived health status, and falling efficacy were 3.0 points in the pre-average and 3.3 points in the post-average, which were statistically significant. The factors that affect the life satisfaction pre-test and post-test applying the physical activity program were perceived health status $(p<0.001)$.

Conclusion: The physical activity program for the elderly is an essential project for the welfare policy for the elderly, and continuous performance and expansion are required.

Key Words: Falling efficacy, Life satisfaction, Perceived health status, Physical activity

\section{INTRODUCTION}

The age standard for the elderly varies slightly depending on the statute or the viewpoint, but the Elderly Act and the WHO define an elderly person as someone aged 65 years and older. The International Association of Gerontology (IAG) says an elderly individual is "the person in the process of complex forms where physiological, psychological, economic and behavioural changes appear in the process of human ageing interact". ${ }^{1}$ As of $2018,14.3 \%$ of Korean society is made up of the elderly, and by 202517 cities and provinces will become super-aged societies within 30 years. ${ }^{2}$ The healthy age in Korea is 73 years, and life expectancy is 82.3 years. The difference between the two is 9.3 years. ${ }^{3}$ In 2015 , the National Statistical Office estimated that the number of elderly households to increase 2.9 times from about 3.66 million in 2015 to about 10.65 million in 2045. The number of elderly single households among all elderly households will increase 3.1 times, and the number of elderly couple house- holds will increase 2.6 times. ${ }^{4}$ Modern medicine and a low birth rate have increased the average life expectancy, leading to a rapid increase in the elderly population and increasing interest in health issues related to the elderly. ${ }^{5}$

Many elderly people have various problems related to the quality of life due to chronic diseases. Ageing of the human body starts at age 40 , including changes in the skeletal system, a quantitative reduction of muscles due to muscle control disorder, declines in overall exercise ability and function related to muscle strength, agility, flexibility, endurance, etc., a decrease in the quality of life, and difficulties performing independent daily life activities. ${ }^{6,78}$

In general, the elderly show changes in the skeletal system and changes in the body due to hormonal changes decreased motor nerves and weakened musculoskeletal functions. As a typical change in the body, the length of the vertebrae gradually decreases due to the pressure of the spine, and the waist is bent, or the curvature of the thoracic and cervical vertebrae

\section{Corresponding Author:}

Young Hee Nam, Department of Health administration NamseoulUniversity, Chungnam, Korea. Email: yhnam14@nsu.ac.kr

ISSN: $2231-2196$ (Print) ISSN: 0975-5241 (Online)

Received: 12.06 .2020

Revised: 14.07 .2020

Accepted: 06.08 .2020

Published: 22.08 .2020 
becomes severe, and the head is bent forward. Falling accidents are one of the most prominent problems caused by the reduction of the independent physical capacity of the elderly. Falling is one of the most frequently seen problems in the ageing process, from minor injuries such as contusions and sprains to serious injuries such as fractures and dislocations. Poor musculoskeletal function in the elderly makes normal walking difficult and increases the risk of falls. This is because as the age increases, the range of motion of the joint decreases due to mechanical properties.

In a 2015 community health survey, the incidence of falls in the elderly was approximately $20 \%$, or one in five elderly people experience falls. ${ }^{9}$ Approximately $3.7 \%$ of men and women aged 65 and over have experienced a fall; this figure is much higher in women $(68.8 \%)$ than in men $(31.2 \%) .{ }^{9}$ The lower leg muscle strength of elderly women decreases more rapidly than that of men, ${ }^{10}$ and the rate of joint disease and imbalances increases, such as in the knee and hip joints. ${ }^{11}$ Elderly people living alone have a higher risk of falling due to the lack of general care. ${ }^{9}$ Serious injuries, such as hip fractures, are usually not recovered to their previous functional level and are reported to increase the chance of death to $37 \%$, ${ }^{2}$ the fall problem has emerged as a serious problem in the satisfaction of life in old age. ${ }^{3}$

Ageing can drastically reduce life quality due to physical and functional deterioration. The purpose of this study is to conduct a physical activity program in an elderly population to assess positive ageing, the facilitation of daily activities, and life satisfaction. This research provides basic data for initiating an effective physical activity program for the elderly by analyzing life satisfaction, perceived health status, falling efficacy, and factors affecting life satisfaction before and after the program.

\section{METHOD}

\section{Research subject}

This single-group pretest-posttest quasi-experimental study was conducted for 12 weeks with the cooperation of the M public health clinic in $\mathrm{H}$ city, Gyeonggi-do Korea. The physical activity program was conducted for elderly people aged 65 and over in rural areas.

The subjects of this study were elderly people (aged 65 years and older), who have never participated in a physical activity program, in a rural area in $\mathrm{H}$ city, Gyeonggi-do. After fully explaining the purpose and content of the study, 34 people provided consent and were selected as the final subjects. The program was conducted once a week for 12 weeks from January to March of 2019. A muscular strength test and questionnaire were conducted at weeks 1 and 12. Each physical activity session was between 60 and 70 minutes.

\section{RESEARCH TOOLS}

\section{General characteristics}

The questionnaire included questions on gender, age, spouse, cohabitation type, number of children, education level, religion, economic level, falling experience, and number of chronic diseases. The age ranges were the $60 \mathrm{~s}, 70 \mathrm{~s}, 80 \mathrm{~s}$, and the cohabitation type was single or married, the children category was two or more, and the education level was divided into six years or nine years or more. The number of chronic diseases was divided into one or less or two or more, and the economic level was divided into high, middle, and low.

\section{Life satisfaction}

Life satisfaction is a concept that includes subjective wellbeing ${ }^{12}$, it is to find meaning for one's life with the joy of daily life, to think of it as worthwhile, to have a positive self-image and to maintain an optimistic attitude and feelings. This study was composed of five items translated by reference ${ }^{13}$ on the reference ${ }^{14}$ life satisfaction scale and Korean life satisfaction scale (K-SWLS). This five-point scale ranges from 'not at all' to 'very yes'. A higher score indicates a higher life satisfaction. The mean of the total items was used as the life satisfaction variables. The Cronbach's score was 0.856 in the pre-test and 0.911 in the post-test.

\section{Perceived health status}

Perceived health status is an indicator of the overall health status of individuals and is a subjective health condition ${ }^{15}$. Perceived health status perceived by the elderly has a significant relationship with depression. In other words, it can be said that the perceived health status of the elderly is the most powerful factor in explaining old age depression. The perceived health status used in this study is Speake et al., ${ }^{16}$ a tool supplemented with three items. This five-point scale ranges from 'very bad' to 'very good'. The higher the score, then higher will be the perceived health status. The mean of the total items was used as the perceived health status variables. The Cronbach's score was 0.851 in the pre-test and 0.878 in the post-test.

\section{Falling efficacy}

Falling efficacy refers to the degree of self-confidence that one will not fall while performing specific activities. ${ }^{17}$ When there is a fall experience, there is a great fear of falling. Fear of falling and anxiety syndrome after falling leads to a decrease in falling efficacy, which is a factor that increases the risk of falling by reducing the passive attitude and physical activity to exercise. In this study, FESI (Falls Effectiveness Scale-International), developed by Yardley et al., ${ }^{18}$ was modified with nine items from the Korean type falling efficacy scale (FES-K) modified by reference. ${ }^{19}$ It is a five-point scale ranging from 'very unconfident' to 'very confident'. The 
higher the score, the higher the falling efficacy. The mean of the total items was used as the falling efficacy variable. The Cronbach's score was 0.948 in the pre-test and 0.934 in the post-test as mentioned in Table $\mathbf{1 .}$

Table 1: Reliability analysis of major variables

\begin{tabular}{lccc} 
Variables & Item number & \multicolumn{2}{c}{ Cronbach's $\alpha$} \\
pre-test & post-test \\
Life satisfaction & 5 & 0.856 & 0.911 \\
$\begin{array}{l}\text { Perceived health } \\
\text { status }\end{array}$ & 3 & 0.851 & 0.878 \\
Falling efficacy & 9 & 0.948 & 0.934 \\
\hline
\end{tabular}

\section{Physical activity program}

The physical activity program used in this study included gymnastics for balance and strength. In other words, it is an exercise that effectively aligns the skeleton and muscles at the same time by maximizing the range of motion of the hip joint, knee joint, and ankle joint to stabilize the spine and maintain the correct posture, thereby normalizing the movement ability and making the correct alignment of the spine. It was organized with the help of instructors and health and athletic experts with many years of community health clinic experience. The warm-up and finish exercises were for five minutes each, and the main exercise session was 60 minutes (Table 2).

Table 2: Physical activity program

\begin{tabular}{|c|c|c|c|}
\hline Classification & Contents & Time & Remark \\
\hline $\begin{array}{l}\text { Introduction } \\
\text { and } \\
\text { termination }\end{array}$ & $\begin{array}{l}\text { - Orientation } \\
\text { - Health education } \\
\text { - Survey }\end{array}$ & 6omin & $\begin{array}{l}1 \text { week and } \\
\text { 12weeks }\end{array}$ \\
\hline Warming-up & $\begin{array}{l}\text { - Major joint exer- } \\
\text { cise } \\
\text { - Stretching and } \\
\text { massage }\end{array}$ & $5 \mathrm{~min}$ & $2 \sim 11 w e e k s$ \\
\hline \multirow[t]{2}{*}{ Main exercise } & $\begin{array}{l}\text { - Basic physical } \\
\text { activity }\end{array}$ & 2omin & \\
\hline & $\begin{array}{l}\text { - Advanced physi- } \\
\text { cal activity } \\
\text { - Leg exercise } \\
\text { - Neck exercise } \\
\text { - Upper body exer- } \\
\text { cise } \\
\text { - Spine extension } \\
\text { - Waist exercise } \\
\text { - Knee exercise } \\
\text { - Thigh exercise } \\
\text { (squat) }\end{array}$ & 4omin & \\
\hline Finish exercise & $\begin{array}{l}\text { - Major joint exer- } \\
\text { cises and stretch- } \\
\text { ing } \\
\text { - Release neck and } \\
\text { shoulders }\end{array}$ & $5 \mathrm{~min}$ & \\
\hline
\end{tabular}

\section{DATA COLLECTION}

Data collection was conducted from January to March of 2019. Information on the method of physical activity, the survey, time required, and participation or withdrawals were explained. Researchers and research assistants surveyed the questions by reading and writing them down. Data collection was conducted on week 1 and week 12 of the physical activity program.

\section{DATA ANALYSIS}

All data collected were analyzed by SPSS 23.0.

1. Data analysis was conducted by calculating the average and standard deviation of variables by the group through descriptive statistics.

2. Paired t-tests were conducted for the homogeneous variables.

3. Independent t-test and ANOVA analysis were conducted for the pre-test and post-test variables to verify homogeneity

4. Multiple linear regressions were performed to determine the factors affecting life satisfaction.

5. The significance level of all statistical processing was set at 0.05 .

\section{RESULTS}

\section{Subject's general characteristics}

Table 3 shows the general characteristics of the study subjects.

The general characteristic of this study was that the proportion of women $(94.1 \%)$ was very high compared to men (5.9The age was the highest among the 70-79-year-olds at $44.1 \%$, followed by the $80-89$-year-olds at $38.2 \%$. The average age was $76.09( \pm 7.37)$ years old.

There were $64.7 \%$ of spouses (including bereavement or divorce), and $52.9 \%$ were living alone. The average number of children was $3.68( \pm 1.55)$. The average education level was 6.91( $( \pm 2.39)$. For religion, 38.2\% were Buddhists, the economic level was $61.8 \%$ of the middle. The fall experience was $29.4 \%$, and the non-fall experience was $70.6 \%$, but the fall experience was also high at about $30 \%$. Two chronic diseases were $41.2 \%$, and three or more were $35.3 \%$. The average was $2.29( \pm 1.24)$ and the maximum was 5 . In this study, $76.5 \%$ of the subjects had two or more chronic diseases. 
Table 3: General characteristics of subjects

\begin{tabular}{|c|c|c|c|c|c|}
\hline Classification & & $\mathbf{N}$ & $\%$ & $\mathrm{M}( \pm \mathrm{SD})$ & Range \\
\hline \multirow[t]{2}{*}{ Gender } & Male & 2 & 5.9 & & \\
\hline & Female & 32 & 94.1 & & \\
\hline \multirow[t]{3}{*}{ Age } & $65-69$ & 6 & 17.6 & $76.09( \pm 7.37)$ & $6 o-88$ \\
\hline & $70-79$ & 15 & 44.1 & & \\
\hline & $80-89$ & 13 & 38.2 & & \\
\hline \multirow[t]{2}{*}{ Spouse } & Yes & 12 & $35 \cdot 3$ & & \\
\hline & No & 22 & 64.7 & & \\
\hline \multirow[t]{3}{*}{ Cohabitation type } & Alone & 18 & 52.9 & & \\
\hline & Couples & 7 & 20.6 & & \\
\hline & Two generations or more & 9 & 26.5 & & \\
\hline \multirow[t]{2}{*}{ Children(n) } & $\geq 2$ & 7 & 20.6 & $3.68( \pm 1.55)$ & $1-8$ \\
\hline & $\leq 3$ & 27 & $79 \cdot 4$ & & \\
\hline \multirow[t]{2}{*}{ Education level } & $\geq 6$ year & 29 & 85.3 & $6.91( \pm 2.39)$ & $6-16$ \\
\hline & $\leq$ yyear & 5 & 14.7 & & \\
\hline \multirow[t]{4}{*}{ Religion } & Christianity & 10 & 29.4 & & \\
\hline & Buddhism & 13 & 38.2 & & \\
\hline & Catholicism & 3 & 8.8 & & \\
\hline & None & 8 & 23.5 & & \\
\hline \multirow[t]{3}{*}{ Economic level } & High & 2 & 5.9 & & \\
\hline & Middle & 21 & 61.8 & & \\
\hline & Low & 11 & 32.4 & & \\
\hline \multirow[t]{2}{*}{ Falling experience } & Yes & 10 & 29.4 & & \\
\hline & No & 24 & 70.6 & & \\
\hline \multirow[t]{3}{*}{ Chronic diseases(n) } & $\geq 1$ & 8 & 23.5 & $2.29( \pm 1.24)$ & $0-5$ \\
\hline & 2 & 14 & 41.2 & & \\
\hline & $\leq 3$ & 12 & 35.3 & & \\
\hline
\end{tabular}

\section{Descriptive statistics of variables related to life satisfaction}

Descriptive statistics on the variables related to life satisfaction are in Table 4. For the data test, the study analyzed the skewness and kurtosis of individual items and the average scores for life satisfaction, perceived health status, and falling efficacy.

The average value of life satisfaction was $3.02( \pm 0.72)$ in pre-test and $3.20( \pm 0.80)$ in post-test, and the average value of perceived health status was $2.79( \pm 0.78)$ in pre-test and $3.05( \pm 0.84)$ in post-test. The average value of falling efficacy was $3.17( \pm 0.98)$ in pre-test and $3.54( \pm 0.86)$ in posttest. The measured value of the variables used in this study is assumed to be less than 3 absolute values of the skewness and a normal distribution of less than 10 absolute values of kurtosis $^{20}$. There was no problem with the path analysis of this data.

Table 4: Descriptive statistics of major variables

\begin{tabular}{llcccccc} 
Variables & & Minimum value & Maximum value & Mean & Standard Deviation & Skewness & Kurtosis \\
Life satisfaction & pre-test & 1.60 & 4.60 & 3.02 & 0.72 & -0.03 & -0.48 \\
& post-test & 2.00 & 4.60 & 3.20 & 0.80 & -0.13 & -1.10 \\
Perceived health & pre-test & 1.00 & 4.67 & 2.79 & 0.78 & 0.39 & 0.40 \\
status & post-test & 2.00 & 4.67 & 3.05 & 0.84 & -0.79 \\
Falling efficacy & pre-test & 1.44 & 5.00 & 3.17 & 0.98 & -0.17 & -1.07 \\
& post-test & 2.00 & 5.00 & 3.54 & 0.86 & -0.95 \\
\hline
\end{tabular}


Verification of samples of major variables beforeandafterthe physical activity program

Table 5 is an average comparison of the main variables before and after the physical activity program.

The average of the main variables was significantly higher after the physical activity program. The significant level of life satisfaction and perceived health status was $\mathrm{p}<0.05$, and the level of falling efficacy was $p<0.001$. Therefore, there were significant changes in falling efficacy, life satisfaction, and perceived health status following the program.

Table 5: Mean difference of major variables before and after physical activity program

\begin{tabular}{llccc} 
Variables & & $\begin{array}{c}\text { Mean } \\
( \pm \text { MD })\end{array}$ & t & P \\
Life satisfaction & pre-test & $2.79( \pm .78)$ & -2.898 & $0.007^{*}$ \\
& post-test & $3.05( \pm .84)$ & & \\
Perceived & pre-test & $3.02( \pm .72)$ & -2.182 & $0.036^{* *}$ \\
health status & post-test & $3.20( \pm .80)$ & & \\
Falling efficacy & pre-test & $3.17( \pm .98)$ & -3.969 & $0.000^{* * * *}$ \\
& post-test & $3.54( \pm .86)$ & & \\
\hline
\end{tabular}

${ }^{*} \mathrm{p}<0.05,{ }^{* *} \mathrm{p}<0.01,{ }^{* * * *} \mathrm{p}<0.001$

\section{Differences in life satisfaction, perceived} health status, and falling efficacy according to general characteristics

Table 6 analyzes the differences between life satisfaction, perceived health status, and falling efficacy according to general characteristics, before and after a physical activity program.

Before the physical activity program, it was statistically significant in age, cohabitation type, number of children, religion, economic level, and number of chronic diseases. After the physical activity program, it was statistically significant in age and number of chronic diseases. Before and after physical activity programs, life satisfaction perceived health status, and falling efficacy according to general characteristics showed overall high scores after the program.

Before the physical activity program, age was significant in falling efficacy $(\mathrm{F}=9.377, p=0.001)$, and falling efficacy decreased as the age increased. After the physical activity program, age was significant in life satisfaction $(\mathrm{F}=3.895$, $p=0.031)$ and falling efficacy $(\mathrm{F}=5.119, p=0.012)$. The highest order of life satisfaction was in the order of $60 \mathrm{~s}, 80 \mathrm{~s}$, and $70 \mathrm{~s}$, and the highest order of falling efficacy was in the order of $60 \mathrm{~s}, 70 \mathrm{~s}$, and $70 \mathrm{~s}$.

Before the physical activity program, perceived health status according to the cohabitation type was significant $(\mathrm{F}=4.064$, $p=0.027)$. The order of high perceived health status according to the cohabitation type was in the order of two generations or more, couples, and living alone.

Before the physical activity program, falling efficacy according to the number of children was significant $(\mathrm{F}=2.237$, $p=0.032$ ). Falling efficacy according to the number of children was higher than 3 children when they were less than 2 children.

Before the physical activity program, life satisfaction according to the religion was significant $(\mathrm{F}=3.158, p=0.039)$. Life satisfaction according to religion was high in the order of Buddhism, Christianity, None, and Catholicism.

Before the physical activity program, life satisfaction according to the economic level was significant $(\mathrm{F}=5.306$, $p=0.010$ ). Life satisfaction according to the economic level was high, middle, and low.

Before and after the physical activity program, perceived health status according to the number of chronic diseases was significant $(\mathrm{F}=3.868, p=0.032, \mathrm{~F}=7.411, p=0.002)$. Before and after the physical activity program, the perceived health status score was the highest when there were 1 or fewer chronic diseases.

Table 6: Differences in life satisfaction perceived health status, and falling efficacy according to general characteristics

\begin{tabular}{|c|c|c|c|c|c|c|c|}
\hline \multirow{2}{*}{\multicolumn{2}{|c|}{ Classification }} & \multicolumn{3}{|c|}{ pre-test $\mathrm{M}( \pm \mathrm{SD})$} & \multicolumn{3}{|c|}{ post-test $\mathrm{M}( \pm \mathrm{SD})$} \\
\hline & & $\begin{array}{c}\text { Life } \\
\text { Satisfaction }\end{array}$ & $\begin{array}{c}\text { Perceived } \\
\text { health status }\end{array}$ & $\begin{array}{l}\text { Falling } \\
\text { efficacy }\end{array}$ & $\begin{array}{c}\text { Life } \\
\text { satisfaction }\end{array}$ & $\begin{array}{c}\text { Perceived } \\
\text { health status }\end{array}$ & $\begin{array}{l}\text { Falling } \\
\text { efficacy }\end{array}$ \\
\hline \multirow{3}{*}{ Gender } & Male & $3.00( \pm 0.28)$ & $2.50( \pm 0.71)$ & $4.11( \pm 0.16)$ & $3.00( \pm 0.28)$ & $2.67( \pm 0.47)$ & $4.11( \pm 0.16)$ \\
\hline & Female & $3.03( \pm 0.74)$ & $2.81( \pm 0.79)$ & $3.12( \pm 0.98)$ & $3.21( \pm 0.82)$ & $3.07( \pm 0.86)$ & $3.50( \pm 0.88)$ \\
\hline & $\mathrm{t}(\mathrm{p})$ & $-0.047(0.963)$ & $-0.542(0.592)$ & $1.411(0.168)$ & $-0.360(0.722)$ & $-0.657(0.516)$ & $0.964(0.342)$ \\
\hline \multirow{4}{*}{ Age } & $65-69$ & $3.53( \pm 0.48)$ & $3.44( \pm 0.69)$ & $4.02( \pm 0.56)$ & $3.67( \pm 0.58)$ & $3.67( \pm 0.84)$ & $4.30( \pm 0.81)$ \\
\hline & $70-79$ & $2.79( \pm 0.85)$ & $2.62( \pm 0.92)$ & $3.45( \pm 0.91)$ & $2.81( \pm 0.82)$ & $2.76( \pm 0.76)$ & $3.62( \pm 0.83)$ \\
\hline & $80-89$ & $3.06( \pm 0.52)$ & $2.69( \pm 0.50)$ & $2.46( \pm 0.75)$ & $3.43( \pm 0.70)$ & $3.10( \pm 0.84)$ & $3.09( \pm 0.69)$ \\
\hline & $\mathrm{F}(\mathrm{p})$ & $2.569(.093)$ & $2.822(.075)$ & 9.377(.oo1) & $3.895(.031)$ & $2.840(.074)$ & $5.119(.012)$ \\
\hline
\end{tabular}


Table 6: (Continued)

\begin{tabular}{|c|c|c|c|c|c|c|c|}
\hline \multirow{2}{*}{\multicolumn{2}{|c|}{ Classification }} & \multicolumn{3}{|c|}{ pre-test $\mathrm{M}( \pm \mathrm{SD})$} & \multicolumn{3}{|c|}{ post-test $\mathrm{M}( \pm \mathrm{SD})$} \\
\hline & & $\begin{array}{c}\text { Life } \\
\text { Satisfaction }\end{array}$ & $\begin{array}{c}\text { Perceived } \\
\text { health status }\end{array}$ & $\begin{array}{l}\text { Falling } \\
\text { efficacy }\end{array}$ & $\begin{array}{c}\text { Life } \\
\text { satisfaction }\end{array}$ & $\begin{array}{c}\text { Perceived } \\
\text { health status }\end{array}$ & $\begin{array}{l}\text { Falling } \\
\text { efficacy }\end{array}$ \\
\hline \multirow{4}{*}{$\begin{array}{l}\text { Marriage } \\
\text { partner }\end{array}$} & Yes & $3.15( \pm 0.76)$ & $3.06( \pm 0.92)$ & $3.47( \pm 0.80)$ & $3.15( \pm 0.76)$ & $3.11( \pm 0.85)$ & $3.69( \pm 0.82)$ \\
\hline & No & $2.95( \pm 0.70)$ & $2.65( \pm 0.68)$ & $3.01( \pm 1.05)$ & $3.23( \pm 0.84)$ & $3.12( \pm 0.86)$ & $3.46( \pm 0.90)$ \\
\hline & $\mathrm{t}(\mathrm{p})$ & $0.753(0.457)$ & $1.463(0.153)$ & $1.324(0.195)$ & $-0.265(0.792)$ & $0.313(0.756)$ & $0.769(0.448)$ \\
\hline & Alone & $2.84( \pm 0.69)$ & $2.50( \pm 0.64)$ & $2.83( \pm 1.10)$ & $3.18( \pm 0.88)$ & $2.96( \pm 0.90)$ & $3.35( \pm 0.90)$ \\
\hline \multirow{3}{*}{$\begin{array}{l}\text { Cohabita- } \\
\text { tion } \\
\text { Type }\end{array}$} & Couples & $2.97( \pm 0.56)$ & $2.86( \pm 0.57)$ & $3.51( \pm 0.59)$ & $2.97( \pm 0.56)$ & $2.86( \pm 0.57)$ & $3.60( \pm 0.78)$ \\
\hline & $\begin{array}{l}\text { Two gen- } \\
\text { erations or } \\
\text { more }\end{array}$ & $3.42( \pm 0.80)$ & $3.33( \pm 0.94)$ & $3 \cdot 59( \pm 0.77)$ & $3.42( \pm 0.80)$ & $3 \cdot 37( \pm .89)$ & $3.86( \pm 0.85)$ \\
\hline & $\mathrm{F}(\mathrm{p})$ & $2.095(0.140)$ & $4.064(0.027)$ & $2.508(0.098)$ & $0.625(0.542)$ & $0.929(0.406)$ & $1.84(0.351)$ \\
\hline \multirow{3}{*}{ Children(n) } & $\geq 2$ & $3.46( \pm 0.43)$ & $3.24( \pm 0.90)$ & $3.87( \pm 0.62)$ & $3.34( \pm 0.59)$ & $3.24( \pm 0.90)$ & $4.08( \pm 0.80)$ \\
\hline & $\leq 3$ & $2.91( \pm 0.74)$ & $2.68( \pm 0.73)$ & $2.99( \pm 0.99)$ & $3.16( \pm 0.85)$ & $3.00( \pm 0.84)$ & $3.40( \pm 0.84)$ \\
\hline & $\mathrm{t}(\mathrm{p})$ & $1.858(0.072)$ & $1.734(0.093)$ & $2.237(0.032)$ & $0.524(0.604)$ & $0.661(0.513)$ & $1.931(0.062)$ \\
\hline \multirow{3}{*}{$\begin{array}{l}\text { Education } \\
\text { level }\end{array}$} & $\geq$ 6year & $3.06( \pm 0.68)$ & $2.79( \pm 0.76)$ & $3.10( \pm 0.95)$ & $3.24( \pm 0.79)$ & $3.07( \pm 0.85)$ & $3.45( \pm 0.82)$ \\
\hline & $\leq$ 9year & $2.84( \pm 1.01)$ & $2.80( \pm 1.02)$ & $3.62( \pm 1.17)$ & $2.96( \pm 0.91)$ & $2.93( \pm 0.86)$ & $4.07( \pm 1.05)$ \\
\hline & $\mathrm{t}(\mathrm{p})$ & $0.613(.544)$ & -0.018(.986) & $-1.109(.276)$ & $0.721(.476)$ & $0.328(.745)$ & $-1.506(.142)$ \\
\hline \multirow{5}{*}{ Religion } & $\begin{array}{l}\text { Christian- } \\
\text { ity }\end{array}$ & $3.20( \pm 0.73)$ & $2.87( \pm 0.93)$ & $3.17( \pm 1.08)$ & $3.38( \pm 0.83)$ & $3.23( \pm 0.94)$ & $3.58( \pm 1.05)$ \\
\hline & Buddhism & $3.29( \pm 0.63)$ & $2.90( \pm 0.84)$ & $3 \cdot 34( \pm 0.97)$ & $3.40( \pm 0.70)$ & $3.08( \pm 0.84)$ & $3.68( \pm 0.78)$ \\
\hline & $\begin{array}{l}\text { Catholi- } \\
\text { cism }\end{array}$ & $2.27( \pm 0.46)$ & $2.33( \pm 0.33)$ & $2.41( \pm 0.39)$ & $2.27( \pm 0.46)$ & $2.33( \pm 0.33)$ & $2.52( \pm 0.45)$ \\
\hline & None & $2.65( \pm 0.45)$ & $2.71( \pm 0.63)$ & $3.19( \pm 1.06)$ & $3.00( \pm 0.80)$ & $3.04( \pm 0.83)$ & $3.64( \pm 0.70)$ \\
\hline & $\mathrm{F}(\mathrm{p})$ & $3.158(0.039)$ & $0.459(0.713)$ & $0.716(0.550)$ & $2.178(0.111)$ & $0.879(0.463)$ & $1.650(0.199)$ \\
\hline \multirow{4}{*}{$\begin{array}{l}\text { Economic } \\
\text { level }\end{array}$} & High & $3.40( \pm 0.85)$ & $3.33( \pm 0.94)$ & $3.22( \pm 0.31)$ & $3.40( \pm 0.85)$ & $3.33( \pm 0.94)$ & $3.22( \pm 0.31)$ \\
\hline & Middle & $3.26( \pm 0.63)$ & $2.94( \pm 0.71)$ & $3 \cdot 38( \pm 0.96)$ & $3.37( \pm 0.74)$ & $3.08( \pm 0.82)$ & $3.71( \pm 0.74)$ \\
\hline & Low & $2.51( \pm 0.64)$ & $2.42( \pm 0.82)$ & $2.77( \pm 1.04)$ & $2.84( \pm 0.86)$ & $2.94( \pm 0.93)$ & $3.26( \pm 0.94)$ \\
\hline & $\mathrm{F}(\mathrm{p})$ & $5 \cdot 306(0.010)$ & $2.198(0.128)$ & $1.443(0.252)$ & $1.758(0.189)$ & $0.211(0.811)$ & $1.138(0.333)$ \\
\hline \multirow{3}{*}{ Fall } & Yes & $3.02( \pm 0.88)$ & $2.73 \pm 0.84)$ & $2.81( \pm 0.94)$ & $3.12( \pm 0.93)$ & $2.83( \pm 0.81)$ & $3.16( \pm 0.28)$ \\
\hline & No & $3.03( \pm 0.66)$ & $2.82( \pm 0.77)$ & $3.32( \pm 0.98)$ & $3.23( \pm 0.76)$ & $3.14( \pm 0.86)$ & $3.70( \pm 0.82)$ \\
\hline & $\mathrm{t}(\mathrm{p})$ & -0.018(.986) & $-.288(.775)$ & $-1.406(.169)$ & $-.371(.713)$ & $-.964(.342)$ & $-1.720(.095)$ \\
\hline \multirow{4}{*}{$\begin{array}{l}\text { Chronic } \\
\text { diseases(n) }\end{array}$} & $\geq 1$ & $3.33( \pm 0.78)$ & $3.33( \pm 0.87)$ & $3 \cdot 54( \pm 1.08)$ & $3.68( \pm 0.73)$ & $3.83( \pm 0.86)$ & $4.01( \pm 0.88)$ \\
\hline & 2 & $3.09( \pm 0.73)$ & $2.81( \pm 0.78)$ & $3.21( \pm 1.02)$ & $3.26( \pm 0.84)$ & $3.00( \pm 0.69)$ & $3 \cdot 57( \pm 0.92)$ \\
\hline & $\leq 3$ & $2.75( \pm 0.62)$ & $2.42( \pm 0.52)$ & $2.88( \pm 0.85)$ & $2.82( \pm 0.65)$ & $2.58( \pm 0.64)$ & $3.19( \pm 0.86)$ \\
\hline & $\mathrm{F}(\mathrm{p})$ & $1.696(0.200)$ & $3.868(0.032)$ & $1.116(0.341)$ & $3.200(0.055)$ & $7.411(0.002)$ & $2.414(0.106)$ \\
\hline
\end{tabular}

Factors affecting life satisfaction of before and after applying for physical activity program

Table 7 shows the results of controlling general characteristics and verifying that physical activity programs affect life satisfaction. As a result of confirming the multicollinearity of the variables in Table 7, the tolerance limits were 0.699 in pre-test and 0.598 in post-test, which was 0.1 or more. The Variance inflation factor (VIF) was less than 10 with 1.432 in pre-test and 1.672 in post-test, so the regression model had no problems.
Before the physical activity program, the explanatory power of factors affecting life satisfaction was $65.4 \%$. After the physical activity program, the explanatory power of factors affecting life satisfaction was $66.7 \%$.

The perceived health status was statistically significant before and after the physical activity program $(\mathrm{p}<0.001)$. The falling efficacy was not statistically significant before and after the physical activity program was applied. Therefore, the better the perceived health status, higher life satisfaction. 
Table 7: Factors affecting life satisfaction beforeandafter physical activity program application

\begin{tabular}{|c|c|c|c|c|c|c|c|c|}
\hline Variables & & B & SE & $\beta$ & $\mathbf{t}$ & $\mathbf{p}$ & Tolerance & VIF \\
\hline \multirow{4}{*}{ Pre-test } & (constant) & 1.017 & 0.304 & & 3.348 & 0.002 & & \\
\hline & $\begin{array}{l}\text { Perceived health } \\
\text { status }\end{array}$ & 0.773 & 0.116 & 0.843 & 6.666 & 0.000 & 0.699 & 1.432 \\
\hline & Fall efficacy & -0.049 & 0.092 & -0.067 & -0.527 & 0.602 & 0.699 & 1.432 \\
\hline & \multicolumn{8}{|c|}{$\mathrm{R}_{2}=.654$ Adj $\mathrm{R}_{2}=.631 \mathrm{~F}=29.246 p=0.000$} \\
\hline Variables & & B & SE & $\beta$ & $\mathrm{t}$ & $\mathrm{p}$ & Tolerance & VIF \\
\hline \multirow{4}{*}{ Post-test } & (constant) & 0.799 & 0.366 & & 2.181 & 0.037 & & \\
\hline & $\begin{array}{l}\text { Perceived health } \\
\text { status }\end{array}$ & 0.762 & 0.127 & 0.801 & 5.976 & 0.000 & 0.598 & 1.672 \\
\hline & Fall efficacy & 0.022 & 0.124 & 0.024 & 0.178 & -0.231 & 0.598 & 1.672 \\
\hline & \multicolumn{8}{|c|}{$\mathrm{R}_{2}=.667$ Adj $\mathrm{R}_{2}=.654 \mathrm{~F}=31.011 p=0.000$} \\
\hline
\end{tabular}

\section{DISCUSSION}

This study was conducted to investigate the effects of physical activity programs on life satisfaction of elderly people in rural areas. The results were drawn before and after the 12-week physical activity program for elderly people aged 65 and over. Elderly individuals who engaged in physical activity program had significant changes in life satisfaction, perceived health status, and falling efficacy.

Ageing and lack of exercise in the elderly cause muscle weakness and posture imbalance, which causes inconvenience in walking and daily life, as well as a decrease in life satisfaction due to respiratory diseases such as pneumonia and falls and fractures. As a result of examining the changes of major variables with the same measurement tool before and after applying for the physical activity program, the average value of life satisfaction perceived health status, and falling efficacy showed a significant increase after applying for the physical activity program. Reference, ${ }^{21}$ the perceived health status and falling efficacy were significantly increased after applying Tai Chi exercise. Reference, ${ }^{22}$ as a result of performing Pilates mat exercise on 6 adult males, the change in the posture of the head and pelvis was statistically significant. These results would have been the vitality and motivation of life for the elderly to exercise periodically with the same age group. Besides, the group that performed the Tai Chi exercise for more than 10 years had the highest life satisfaction..$^{21}$ The physical activity program applied in this study also requires continuous performance rather than short-term application, and long-term performance is improved more than the current results, which will improve the perceived health condition and falling efficacy.

The difference in life satisfaction perceived health status, and falling efficacy according to the general characteristics of the subjects was significant before and after the application of the physical activity program, which was the number of age and chronic diseases. The age group was 65 years old, that is, the younger the elderly, the higher the fall efficacy, and the perceived health condition was significantly higher when the number of chronic diseases was less than one. In this study, the number of chronic diseases in the elderly was $76.5 \%$ and up to 5 in the case of two or more cases. The elderly with more chronic diseases had lower life satisfaction, perceived health status, and falling efficacy. When the number of chronic diseases is more than 3 , the incidence of falls is 1.1-1.5 times higher, ${ }^{9}$ and the confidence in health is decreased due to chronic diseases, and the fear of falls is increased.

Especially, it was found that the subjects with low life satisfaction improved significantly perceived health status after applying for the physical activity program. The final factor affecting life satisfaction was perceived health status, which showed the same result as previous studies. ${ }^{21,23,24}$ This perceived health condition also has a significant effect on daily life performance ability. ${ }^{25,26,27}$ It is very important to prepare for the solution for effective policy preparation to prepare for the weakening of daily life performance ability that is inevitably inevitable for the elderly due to the increase in average life expectancy and changes in the type of household. ${ }^{28}$ The ageing caused by chronic diseases and age increase causes discomfort and obstacles to the performance and activities of everyday life, and it seems to have been a factor that lowers the quality of life and lowers the satisfaction. Therefore, physical activity serves as a vital element for the elderly's life and raises the satisfaction of life, so it is recommended that the more the patients with chronic diseases participate actively in the physical activity program.

The perceived health status was higher when the two or more families lived together, and the elderly living alone had a higher experience of falling than when the couple lived together. Reference also said that the perceived health condition was very low, as the fall was 1.33 times higher than 
the case where the fall was not. ${ }^{29}$ The elderly living alone is shown to be the result of daily life such as food and shelter, and the absence of family that can help in emergencies. Old and Old care(the old man supports the old man) in individual households is mainly a reality that women provide care, and there is a possibility that it will have a fatal health adverse effect on spouses who are in the process of ageing during care. ${ }^{28}$ In Korea, which entered the ageing society in 2018, it is not an option but a necessity to activate the physical activity program for the elderly. Physical activities should be placed on the priority for living a healthy old age, and continuous motivation and performance is very important without going through one-time. Therefore, it is considered that operating a physical activity program for the elderly centred on the local community is an indispensable issue for the welfare policy for the elderly.

\section{CONCLUSION}

As a result of this study, the physical activity of the elderly had significant changes in life satisfaction, perceived health status, and fall efficacy, and the factors affecting life satisfaction were perceived health status. The physical activity program is expected to have a positive effect on strengthening balance ability and strengthening muscle strength through body alignment of the elderly. In particular, it is an effective program for the elderly who are afraid of falling due to the weakening of the lower body muscles. Therefore, it is expected that this program can be applied to small groups in the community at the national level to promote health promotion for the elderly.

In future studies, it is also necessary to follow-up studies on whether physical activity programs affect physical function improvement, stress relief, confidence, and self-esteem. Also, it is necessary to study the measurement of the physical activity applied to the elderly. Therefore, since the physical activity program has a significant effect on the satisfaction of the elderly life, it is necessary to distribute and open various physical activity programs by local governments through health promotion institutions. Also, such physical activity programs are very necessary to provide long-term and sustainable conditions.

This study is the result of the study applying a physical activity program to some elderly people in one rural area of Korea, and it is limited to generalize or expand to all elderly people. Nevertheless, this study confirmed that physical activity has a significant effect on the life satisfaction and perceived health status of the elderly, and it is meaningful to conclude that it should be continuously performed and expanded.

\section{ACKNOWLEDGMENTS}

The funding for this paper was provided by Namseoul University, Chungnam, Korea.

\section{Conflict of Interest: Nil}

Funding Source: Namseoul University, Chungnam, Korea

\section{REFERENCES}

1. S. D. Park. Welfare Theory for the Elderly. Seoul: Samwoosa. 2006.

2. Korea National Statistical Office. 2017 Age Statistics. 2017.

3. WHO. World Health Statistics 2016: Monitoring health for the SDGs. 2016.

4. G. R. Kim, Y. K. Lee, N. H. Hwang, J. Y. Seo, H. W. Bae. Enhancing Daily Living Convenience for Elderly Households through Internalization of the Aging-friendly Industry Method Study. Korea Institute for Health and Social Affairs. 2018.

5. Kim YC, Paik J. The effects of family conflict, social support and self-esteem on life satisfaction of the aged. Journal of Digital Convergence. 2016;14(7):279-87.

6. Leventhal H, Halm E, Horowitz C, Leventhal EA, Ozakinci G. Living with chronic illness: A contextualized, self-regulation approach. The Sage handbook of health psychology. 2004 :197240.

7. Buchmann MC, Kriesi I, Sacchi S. Labour market structures and women's employment levels. Work, Employment and Society. 2010 Jun;24(2):279-99.

8. J. S. Jang. Musculoskeletal Disease of the Elderly. Clinical Guide for the Elderly Disease II. 2009.

9. Byeon K, Nam Y. The Relationship between Status of Chronic Disease and Fall Experience in Korean Elderly: Based on 2015 Community Health Survey. The Journal of Korean Society for School and Community Health Education. 2019; 20(1):113-26.

10. McCarthy C, Dieppe P. Taping the patella medially: a new treatment for osteoarthritis of the knee joint?. Bmj. 1994 Mar 19; 308(6931):753-5.

11. Cummings SR, Browner W, Black DM, Nevitt MC, Genant HK, Cauley J, Ensrud K, Scott J, Vogt TM. Bone density at various sites for prediction of hip fractures. The Lancet. 1993 Jan 9;341(8837):72-5.

12. Diener E. Assessing subjective well-being: Progress and opportunities. In Assessing well-being 2009; 25-29.

13. M. H. Cho, and G. H. Cha. A comparative Study on Quality of Life among Countries. Seoul: Jipmoondang. 1998.

14. Diener ED, Emmons RA, Larsen RJ, Griffin S. The satisfaction with life scale. Journal of personality assessment. 1985 Feb $1 ; 49(1): 71-5$.

15. Farmer MM, Ferraro KF. Distress and perceived health: mechanisms of health decline. Journal of Health and Social Behavior. 1997 Sep 1:298-311.

16. Speake DL, Cowart ME, Pellet K. Health perceptions and lifestyles of the elderly. Research in Nursing and Health. 1989 Apr;12(2):93-100.

17. Tinetti ME, Richman D, Powell L. Falls efficacy as a measure of fear of falling. Journal of gerontology. 1990 Nov 1;45(6):P23943.

18. Yardley L, Beyer N, Hauer K, Kempen G, Piot-Ziegler C, Todd C. Development and initial validation of the Falls Efficacy ScaleInternational (FES-I). Age and ageing. 2005 Nov 1;34(6):614-9. 
19. Huh JH, Lim SK, Lee D. Development of the Korean Falls Efficacy Scale (FES-K) for the elderly. The Korean Journal of Physical Education. 2010 ; 49(3):193-201.

20. Kline RB. Principles and practice of structural equation modeling. Guilford publications; 2015 Nov 3.

21. M. K. Kim. Influence of Perceived Health Status and Fall Efficacy on Life Satisfaction in Older Adults Performing Tai-Chi Exercise. Unpublished master's thesis, Seongshin women's university, Seoul. 2016.

22. Hwang SK. The effects of pilates mat exercises on physical posture and foot balance in male adults. Unpublished Master's Thesis, Myongji University. 2012.

23. Kwon YO, Choi MS, Lee JH, Yun HK. Analysis of structural relationship among geriatric denture-related characteristics, denture satisfaction, and GOHAI. Journal of Digital convergence. 2014;12(4):399-407.

24. Chang KO, Lim JH. Construction of a structural model about the perceived health status, pain, sleep pattern and quality of life in the elderly. Journal of the Korea Academia-Industrial cooperation Society. 2014;15(7):4336-45.
25. Y. H. Nam. The Effects of Physical Activity Programs on Life Satisfaction of the Elderly. Journal of Nursing Methodology. 2020;1(1):25-30.

26. Kim MS, Kim JI. Relationship among the health state, daily living activities (ADL, IADL), sleep state, and depression among old people at elderly care facilities. Journal of the Korea Academia-Industrial Cooperation Society. 2015;16(4):2609-19.

27. Oh S, Ko Y. Activities of daily living, depression, and self-rated health and related factors in Korean elderly: Focused on socioeconomic status and family support. Journal of Korean Academy of Community Health Nursing. 2015 Jun 1;26(2):140-9.

28. K. R. Kim, Y. K. Lee, N. H. Hwang, J. Y. Seo, H. W. Bae. A Study on the Improvement of the Living Convenience for the Elderly Households through the Enhancement of the ElderlyFriendly Industry -Focused on the Elderly-Friendly Uses and Goods. Korea Health and social research institute. 2018.

29. Paliwal Y, Slattum PW, Ratliff SM. Chronic health conditions as a risk factor for falls among the community-dwelling US older adults: a zero-inflated regression modeling approach. BioMed research international. 2017 28;2017. 